\title{
AN INTENSIVE MULTI-SITE PILOT STUDY INVESTIGATING ATMOSPHERIC MERCURY IN BROWARD COUNTY, FLORIDA
}

\author{
J.T. DVONCH ${ }^{1}$, A.F. VETTE ${ }^{1}$, G.J. KEELER ${ }^{1 *}$, G. EVANS $^{2}$ and R. STEVENS ${ }^{2}$ \\ ${ }^{1}$ The University of Michigan Air Quality Laboratory, Ann Arbor, MI $48109^{2}$ USEPA-AREAL \\ * Author to whom correspondence should be addressed
}

\begin{abstract}
An intensive multi-site pilot study of atmospheric $\mathrm{Hg}$ was conducted in Broward County, Florida in August and September of 1993. Broward County, which contains the city of Fort Lauderdale, is located in southeastern Florida. The county borders the Florida Everglades on the west and the Atlantic Ocean on the east. A network of four sampling sites was set up for 20 days throughout Broward County to measure $\mathrm{Hg}$ in both the vapor phase and the particle phase as well as $\mathrm{Hg}$ in precipitation. The mean concentrations of total vapor phase $\mathrm{Hg}$ measured at two inland sites were found to be significantly higher $\left(3.3\right.$ and $2.8 \mathrm{ng} / \mathrm{m}^{3}$ ) than that measured at a site located on the Atlantic shore $\left(1.8 \mathrm{ng} / \mathrm{m}^{3}\right)$. The mean concentrations of particle phase $\mathrm{Hg}$ collected at the two inland sites $\left(51\right.$ and $\left.49 \mathrm{pg} / \mathrm{m}^{3}\right)$ were found to be $50 \%$ greater than that measured at the coastal site $\left(34 \mathrm{pg} / \mathrm{m}^{3}\right)$. In addition, event precipitation samples were collected at four sampling sites over the 20 day study period and were analyzed for both reactive and total $\mathrm{Hg}$. The mean concentration of total $\mathrm{Hg}$ in the precipitation samples was found to be $44 \mathrm{ng} / \mathrm{L}$, with a range of 14 to $130 \mathrm{ng} / \mathrm{L}$. It was determined that further meteorological analysis and a more complete characterization of the acrosol and precipitation composition are needed to identify the probable source(s) contributing to the increased deposition of $\mathrm{Hg}$.
\end{abstract}

\section{Introduction}

The importance of mercury $(\mathrm{Hg})$ as an environmental contaminant stems from its ubiquitous nature due largely to the multitude of sources, its volatility, mobility and persistence in nature. While $\mathrm{Hg}$ was once thought to be a threat only in the locality of large industrial facilities, recent research has found that even remote and pristine waters have elevated levels of $\mathrm{Hg}$ compounds in fish. A statewide survey of $\mathrm{Hg}$ in sportfish was implemented in Florida after preliminary indications of $\mathrm{Hg}$ contamination in Florida freshwater fish (Hand and Friedemann, 1990). The study found concentrations of $\mathrm{Hg}$ in fish in the Savannas State Reserve and the Everglades that exceeded acceptable levels for human consumption. $\mathrm{Hg}$ concentrations sufficient to warrant limited consumption advisories were found in fish in numerous lakes, rivers, and wetlands. Other studies in Florida suggested that $\mathrm{Hg}$ is transported through the Everglades food web and that $\mathrm{Hg}$ bioaccumulation has diminished the viability of the endangered Florida panther (Roelke et al., 1991). The risk of $\mathrm{Hg}$ biomagnification to other animal popvlations has not yet been quantified. However, the potential for perturbations of ecosystem structure and function seems apparent.

The studies described above provided an initial assessment of the magnitude of the $\mathrm{Hg}$ contamination in south Florida. However, they did not address issues regarding the origin, atmospheric transport and deposition, or availability of $\mathrm{Hg}$ in these habitats. The study reported here investigated the local impact of anthropogenic sources on the atmospheric $\mathrm{Hg}$ levels in Broward County, Florida, an area located immediately east of the Florida Everglades. This research was a collaborative effort between the Florida Department of Environmental Protection, the United States Environmental Protection Agency (AREAL and Region IV), the Broward County Department of Natural Resource Protection, and the University of Michigan Air Quality Laboratory (UMAQL). The 
project served as a pilot investigation for more comprehensive sampling to be performed in urban areas in south Florida. The study included a limited investigation of the sampling and analytical methods for atmospheric mercury determinations which could be utilized in selected ecosystems in the Everglades or surrounding areas.

\section{Experimental Methods}

Ambient measurements of vapor phase and particle phase $\mathrm{Hg}$, as well as $\mathrm{Hg}$ in precipitation were made at four sampling sites located in the Fort Lauderdale area (see Figure 1). Samples were collected at each of these sites from 19 August to 7 September, 1993. Since the prevailing winds are out of the east/southeast during the late summer and early fall, a site along the coast was chosen to provide a "local background". Three additional sites were chosen along a path leading inland or "downwind" from the coast. A brief description of each site and the reasons for choosing the site follows.

\subsection{SAMPLING SITES}

The John Lloyd State Park was chosen as the "local background" site (1). The site is also used by the Broward County Department of Natural Resource Protection as a background site for their air monitoring network. The site was located at the end of a service road in the park about $100 \mathrm{~m}$ west of the shore of the Atlantic Ocean and approximately $100 \mathrm{~m}$ east of the Intercoastal Waterway. Samples were collected daily at this site to measure vapor and particle phase $\mathrm{Hg}$ as well as $\mathrm{Hg}$ in precipitation. Since the site was close to the Atlantic Ocean and with winds predominately from the east/southeast, the levels of atmospheric mercury at this site were expected to represent "local background" levels. Because of land-sea breeze circulation, it was understood that this site may not provide a true marine background. However, this site did provide a "local background" for comparison with the three inland sites when winds were out of the east/southeast.

The central site (2) was located on the Broward Community College campus, approximately $13 \mathrm{~km}$ west of site 1 . During periods with winds out of the east/southeast, this site location was expected to provide adequate distance for homogeneous mixing in the boundary layer to assess the impact of local sources. The central site was located on the roof of the campus gymnasium, which was approximately $10 \mathrm{~m}$ high. At site 2, vapor and particulate $\mathrm{Hg}$ samples as well as precipitation samples were collected daily. Another inland site (3) was located approximately $20 \mathrm{~km}$ west of site 1 in the backyard of a residential home. The residential area was moderately populated with several houses in the area adjacent to the sampling site. At this site vapor, particulate and precipitation samples were collected daily. This site was chosen because it was approximately $8 \mathrm{~km}$ east of a conservation area of the Everglades. An additional site (4) was located $10 \mathrm{~km}$ west of site 1 and also approximately $300 \mathrm{~m}$ southwest of a municipal waste incineration facility. Precipitation samples were collected daily at this site which was located on the property of one of the South Florida Water Management District pumping stations on the South New River Canal. 

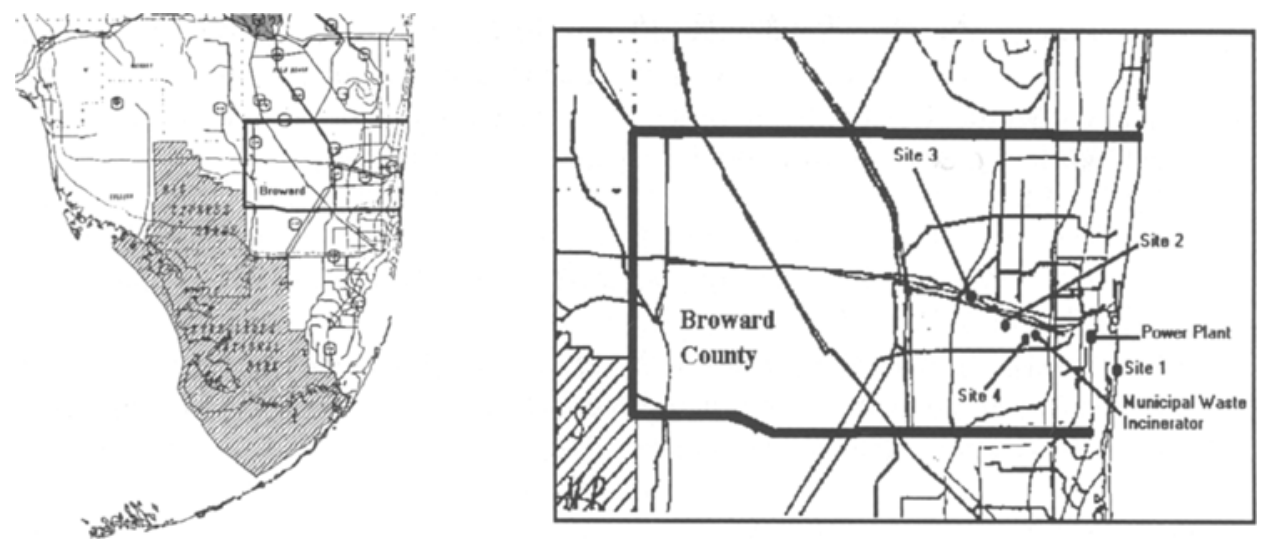

Fig. 1. Location of Sampling Sites in Broward County, FL

\subsection{METHODS OF SAMPLE COLLECTION AND ANALYSIS}

All equipment and supplies used in sampling were rigorously acid-cleaned in an 11day cycle (Hoyer and Keeler, 1994). Sample bottles, gold sand traps and glass-fiber filter containers were Teflon-taped and triple-bagged. All of the samples collected were analyzed using ultra-clean techniques for trace metal analysis. The particulate and precipitation samples were processed and analyzed in a Class 100 ultra-clean laboratory at the UMAQL in order to minimize contamination. However, the vapor phase samples were analyzed on-site in Florida in a normal laboratory setting because the risk of contamination was minimal. Particle-free gloves were worn during all procedures of sample handling and analysis.

\section{Vapor Phase Hg}

Gold-coated sand traps were used at all of the sites because of their ability to quantitatively remove vapor species of $\mathrm{Hg}$ from an air stream. The quartz sand was gold-coated under vacuum in a gold plasma that uniformly deposited gold onto the sand. The collection efficiency of the sand traps for removal of gaseous $\mathrm{Hg}$ has been found to be $>97 \%$ by the UMAQL and by Dumarey et al., (1985). Two traps in series were used to characterize any amount of breakthrough during all measurements of vapor phase $\mathrm{Hg}$. A pre-fired glass-fiber filter (Gelman type A/E) was used to remove particles from the air stream prior to reaching the gold-coated sand traps. Samples were collected at a flow rate of $300 \mathrm{cc} / \mathrm{min}$. for durations varying from 3 to 24 hours. The gold-coated sand traps were analyzed by thermal desorption using a dual amalgamation technique and subsequent analysis by cold vapor atomic fluorescence spectroscopy (CVAFS) similar to the method described by Fitzgerald and Gill (1979). The instrument was calibrated daily by injecting $\mathrm{Hg}$ vapor standards.

\section{Particle Phase Hg}

Particle phase $\mathrm{Hg}$ samples were collected using pre-fired glass-fiber filters (Gelman type $\mathrm{A} / \mathrm{E}$ ). These filters have been proven to efficiently collect particulate $\mathrm{Hg}$ and have 
now been used for three years to measure particulate $\mathrm{Hg}$ levels in the Great Lakes region (Keeler et al., 1995). The filters efficiently capture coarse and fine particles. The filters were run at a nominal flow rate of $30 \mathrm{~L} / \mathrm{min}$. for a duration of 24 hours. After sampling, filters were removed from the filter pack using Teflon coated forceps, placed in an acidcleaned petri dish, Teflon taped and shipped to UMAQL to be stored at $-40^{\circ} \mathrm{C}$ until analysis. The analysis method employed was similar to that previously described (Lamborg et al., 1994). The filters were extracted by sonication for 30 minutes in a $10 \%$ acid solution $\left(7 \% \mathrm{HNO}_{3}: 3 \% \mathrm{H}_{2} \mathrm{SO}_{4}\right)$ in Teflon vials. After sonication, the solution was oxidized with $\mathrm{BrCl}$ followed by reduction with $\mathrm{NH}_{2} \mathrm{OH}$ and $\mathrm{SnCl}_{2}$. The reduced sample was purged onto a gold-coated sand trap and analyzed using the dual amalgamation technique and subsequent analysis by CVAFS.

\section{Hg in Precipitation}

Daily event precipitation samples were collected manually at each site. The collectors consisted of an acid-cleaned $1 \mathrm{~L}$ borosilicate glass sample bottle and a $28 \mathrm{~cm}$ (diameter) polyethylene funnel supported in a polyethylene housing system. The collectors were elevated $2 \mathrm{~m}$ above the ground in order to avoid possible contamination from ground splashing during precipitation. The bottle and funnel were deployed at 8 AM for 24 hours and replaced each morning regardless of a precipitation event. In the event of precipitation occurring at $8 \mathrm{AM}$, the sample was not collected until the completion of the precipitation event. The precipitation samples were shipped to UMAQL by overnight mail for processing and analysis. The analysis method was similar to the one described by Hoyer and Keeler (1994). An aliquot of the sample was poured off for analysis of major ions and samples of sufficient volume were analyzed for the operationally-defined reactive $\mathrm{Hg}$ species by acidifying an aliquot of sample to a $1 \%$ $\mathrm{HCl}$ solution before reduction with $\mathrm{SnCl}_{2}$. In addition, a subset of samples with sufficient volume were poured off into $125 \mathrm{ml}$ polyethylene bottles and acidified to a $0.2 \% \mathrm{HNO}_{3}$ solution for analysis by Inductively Coupled Plasma-Mass Spectrometry (ICP-MS). The analysis method employed was a modification of the procedure described by Long and Martin (1992), using an ultrasonic nebulizer instead of chelation for pre-concentration. The remaining sample volume was oxidized to a $1 \% \mathrm{BrCl}$ solution and refrigerated overnight prior to analysis for total $\mathrm{Hg}$. The oxidized $\mathrm{Hg}$ was reduced and purged onto a gold-coated sand trap and analyzed using the dual amalgamation technique and subsequent analysis by CVAFS.

\section{Additional Trace Constituents}

Measurements of gaseous $\mathrm{SO}_{2}$ were made continuously at site 2 from 28 August to 7 September. These measurements were made using a Differential Optical Absorption Spectrometer (DOAS) as described by Stevens et al., (1993). In addition, aerosol trace metals were also collected at site 2 from 28 August to 7 September using $2-\mu \mathrm{m}$ pore Teflon (PTFE) membrane filters (Gelman) in an all Teflon filter pack. Analysis of these filters was performed at USEPA-AREAL using X-Ray Fluorescence (XRF) similar to the method described by Dzubay et al., (1982). 


\subsection{QUALITY CONTROL AND QUALITY ASSURANCE}

For event precipitation, measurements of the sampling blank were obtained by rinsing the collection funnel with ultra-pure water and analyzing the rinse for $\mathrm{Hg}$. The average concentration of $\mathrm{Hg}$ in 12 precipitation collector blanks was $0.26 \pm 0.2 \mathrm{ng} / \mathrm{L}$. The method of collection used for the present study was slightly different than the automated wet-only sample collection method used in the UMAQL Great Lakes data (Hoyer and Keeler, 1994). With the manual method, the collection bottle was exposed to dry deposition for the entire period that the funnel-bottle was deployed. Since the maximum amount of time that the funnel-bottles were deployed was 24 hours, the amount of $\mathrm{Hg}$ added by dry deposition was negligible relative to the magnitude of $\mathrm{Hg}$ present in the precipitation. The contribution of dry deposition was determined by performing collector rinses on funnels that had been deployed for 24 hours without collecting any precipitation. From the funnel rinses, dry deposition of $\mathrm{Hg}$ to the funnels was found to be insignificant. Furthermore, the manual method used in this study had been previously determined at UMAQL to compare very well to the automated method based on co-located sampling (Hoyer and Keeler, 1994).

Field blanks were collected regularly for vapor phase and particulate $\mathrm{Hg}$ samples. For both types of samples, field blanks were performed by assembling the sampling equipment and placing it in the sampling box without drawing air through the system. Field blanks for vapor phase $\mathrm{Hg}$ averaged $0.015 \mathrm{ng} \mathrm{Hg}$ on the trap, which corresponds to $0.03 \mathrm{ng} / \mathrm{m}^{3}$ for a 24 -hour sample or $1.3 \%$ of the average vapor phase $\mathrm{Hg}$ concentration. Particulate $\mathrm{Hg}$ field blanks averaged $17 \mathrm{pg} \mathrm{Hg}$ on the filter, which corresponds to 0.4 $\mathrm{pg} / \mathrm{m}^{3}$ for a 24 -hour sample or less than $1 \%$ of the particulate $\mathrm{Hg}$ typically collected.

For precipitation and particulate samples, a reagent blank was analyzed on each day of analysis. The appropriate amounts of reagents were analyzed to determine the contribution of the reagents to the concentration of $\mathrm{Hg}$ obtained for the sample. All samples were blank corrected using the corresponding reagent blank analyzed that day. The current detection limit for $\mathrm{Hg}$ in precipitation (calculated as three times the standard deviation of the reagent blanks) is $0.15 \mathrm{ng} / \mathrm{L}$.

All particulate samples and $50 \%$ of precipitation samples were analyzed in duplicate. Analytical precision calculated from these results was better than $10 \%$ for analysis of $\mathrm{Hg}$ in both precipitation and particulate samples.

\section{Results and Discussion}

\subsection{VAPOR PHASE $\mathrm{Hg}$}

Vapor phase Hg levels in Broward County were slightly elevated, on average, above typical background levels reported elsewhere. As seen in Figure 2, concurrent 24-hour averaged vapor phase $\mathrm{Hg}$ concentrations at sites 2 (central) and 3 (house) were found to be significantly different and higher than those at site 1 (beach) as determined from $t-$ tests (paired two-sample comparison of means, $\mathrm{p}<0.01$ ). The elevated $\mathrm{Hg}$ levels at sites 2 and 3 relative to the beach site were most evident for the period 30 August to 7 September. Vapor phase $\mathrm{Hg}$ values observed during the two-week period were elevated 
when compared to typical vapor phase measurements $\left(\sim 2.0 \mathrm{ng} / \mathrm{m}^{3}\right)$ made using the same techniques in the Great Lakes Basin (Keeler et al., 1994).

At site 2 (central) where day and night samples were collected, a strong diurnal relationship was observed in the vapor phase $\mathrm{Hg}$ levels. The average night time vapor phase concentration $\left(4.5 \mathrm{ng} / \mathrm{m}^{3}\right)$ was nearly twice the concentration found during the day time $\left(2.4 \mathrm{ng} / \mathrm{m}^{3}\right)$ at this site. The strong diurnal variation seen in the vapor phase $\mathrm{Hg}$ measurements can be explained by the diurnal changes observed during the study in the structure of the boundary layer in south Florida. During the day time, intense heating resulted in considerable vertical mixing of the ambient pollutants. However, calm winds $(<1.0 \mathrm{~m} / \mathrm{s})$, little vertical mixing, and lower mixing heights during the night resulted in higher concentrations.

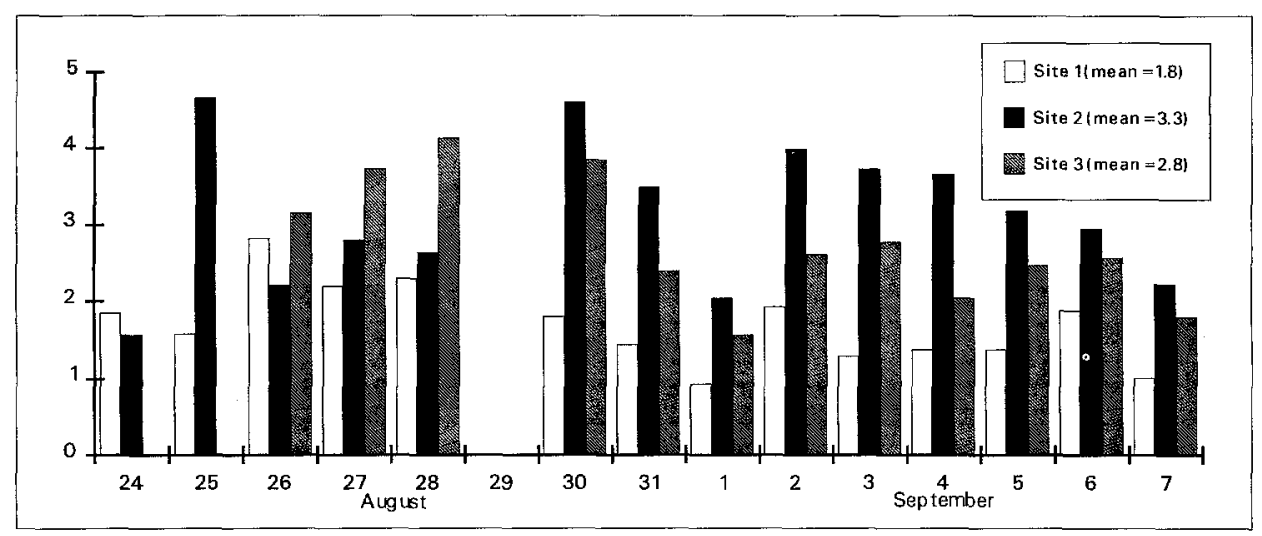

Fig. 2. 24-Hour Averaged Vapor Phase Hg Concentrations in $\mathbf{n g} / \mathrm{m}^{3}$ Measured in Broward County, FL

\subsection{PARTICLE PHASE Hg}

Particulate $\mathrm{Hg}$ samples were taken concurrently at sites 1,2 , and 3 during the period 25 August to 7 September. Figure 3 reveals that the concentrations of particulate $\mathrm{Hg}$ measured at site 2 (central) were significantly ( $p<0.01$ ) elevated with respect to those measured at site 1 (beach), a result also observed with the vapor phase $\mathrm{Hg}$. The average concentrations at site $2\left(51 \mathrm{pg} / \mathrm{m}^{3}\right)$ and site $3\left(49 \mathrm{pg} / \mathrm{m}^{3}\right)$ were $50 \%$ greater than the average at site $1\left(34 \mathrm{pg} / \mathrm{m}^{3}\right)$. As with the vapor phase $\mathrm{Hg}$, this observation was most evident during the period 30 August to 7 September. For measurements made on the days before 30 August, the site to site differences were not as evident due to highly variable meteorological flow patterns that changed notably every several hours during the day. Since 24-hour ambient $\mathrm{Hg}$ measurements were performed at all sites except site 2, most of the time-averaged $\mathrm{Hg}$ measurements made during this study were not of short enough duration to observe site to site differences over short periods of time (less than 12 hours). However, for the period 30 August to 7 September when flow was much more consistent from the east/southeast, the trend of higher vapor phase and particle phase $\mathrm{Hg}$ at sites 2 and 3 compared to site 1 was strongly evident. Consistent air mass transport from the southeast was observed for the period 30 August to 7 September as a result of the semi-permanent Bermuda high. 
Particle phase $\mathrm{Hg}$ comprised less than 5\% of the total atmospheric $\mathrm{Hg}$ (vapor and particulate) for the days with both measurements. This was consistent with other values reported (Burke et al., 1995). The levels of particulate $\mathrm{Hg}$ found during this study were generally higher than those typically measured (about $10-30 \mathrm{pg} / \mathrm{m}^{3}$ ) at rural sites in the Great Lakes Basin (Keeler et al., 1995). In addition, the two-week average of particulate $\mathrm{Hg}$ measured at all sites during this study was 5 to 10 times higher than other measurements made in south Florida (Guentzel et al., 1994). The levels measured in Broward County were not as high as other measurements made in large urban/industrial source areas such as Detroit, where short-term average particulate $\mathrm{Hg}$ concentrations were found to be near $100 \mathrm{pg} / \mathrm{m}^{3}$ (Keeler et. al., 1994; 1995). The elevated levels of particulate $\mathrm{Hg}$ observed in Broward County during this study, however, do suggest a local source influence.

A significant relationship was observed between measurements of aerosol vanadium (V) and gaseous $\mathrm{SO}_{2}$ made at site 2 as seen in Figure 4. Both $\mathrm{V}$ and $\mathrm{SO}_{2}$ are emitted during oil combustion. A relationship was also observed between particle and vapor phase $\mathrm{Hg}$, and $\mathrm{V}$ and $\mathrm{SO}_{2}$, also seen in Figure 4. These relationships were strongest

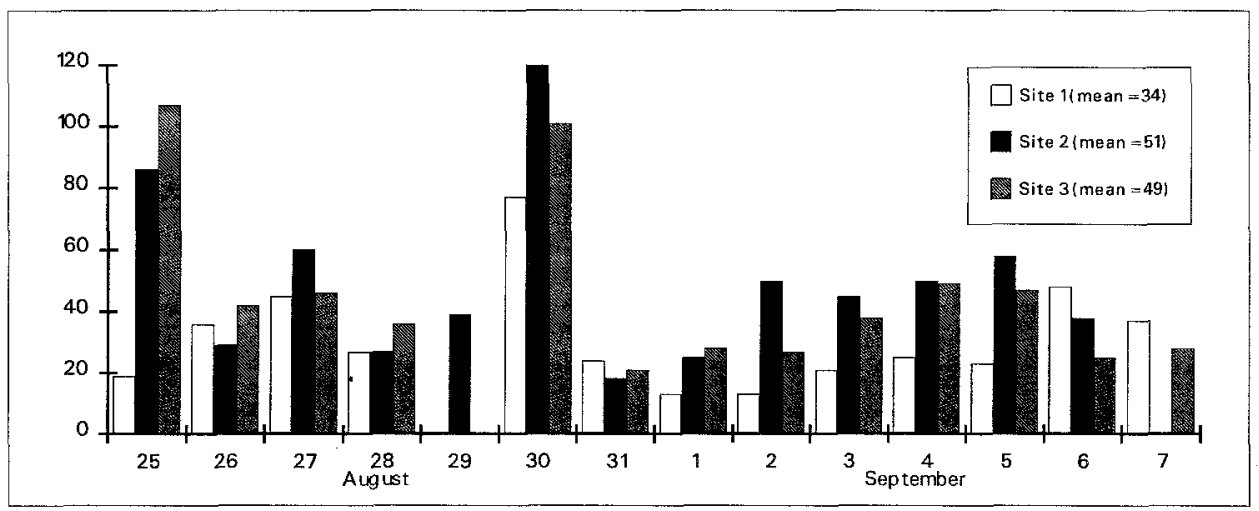

Fig. 3. Particle Phase Hg Concentrations in $\mathrm{pg} / \mathrm{m}^{3}$ Measured in Broward County, FL

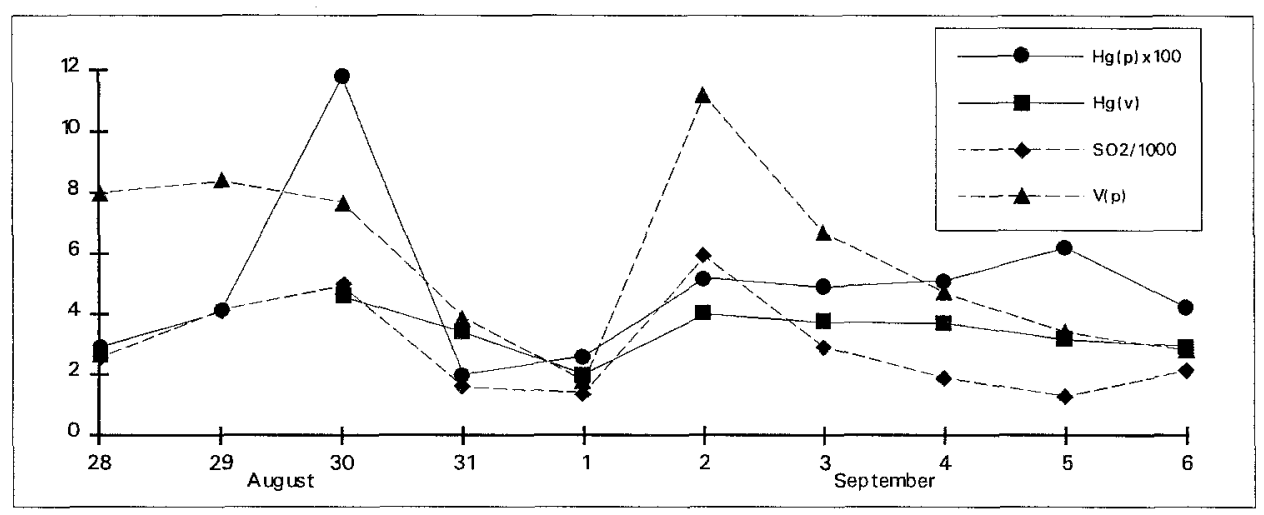

Fig. 4. Particle and Vapor Phase $\mathrm{Hg}$, Particulate $\mathrm{V}$, and Gaseous $\mathrm{SO}_{2}$ in $\mathrm{ng} / \mathrm{m}^{3}$ Measured at Site 2 
during the period 30 August to 2 September. As previously stated, a sea breeze circulation was observed with winds out of the east/southeast during the day, and calm conditions during the night. On 30 August, a sea breeze was present with winds out of the east/southeast corridor during the day. However, Hurricane Emily disrupted the pattern on 31 August and 1 September as it approached the Carolinas and rode up the eastern seaboard. The strong gradient flow caused by the hurricane prevented the typical sea breeze pattern during this 48 -hour period. Sustained winds out of the south/southeast during the entire 2-day period resulted in the cleanest 2 days of the study, as seen in Figure 4. However, on 2 September the hurricane had moved far enough north allowing the Bermuda high to re-establish itself as the dominant feature. The sea breeze circulation was then again present, and as seen in Figure 4, the concentrations of all 4 components were again elevated.

\section{3. $\mathrm{Hg}$ in EVENT PRECIPITATION}

The levels of $\mathrm{Hg}$ measured in precipitation collected at the four sites are summarized in Table I. Average total $\mathrm{Hg}$ concentrations measured at sites 2 (central), 3 (house), and 4 (near incinerator) were elevated relative to concentrations measured at site 1 (beach). All samples collected were analyzed for total $\mathrm{Hg}$ and samples of sufficient volume were analyzed for reactive $\mathrm{Hg}$. Table I suggests that the same pattern seen for total $\mathrm{Hg}$ was also present for reactive $\mathrm{Hg}$ since the average concentrations of reactive $\mathrm{Hg}$ were also elevated at sites 2,3 , and 4 relative to site 1 . However, this trend was not as distinct for $\mathrm{Hg}$ in precipitation as it was for vapor phase and particle phase $\mathrm{Hg}$.

It should be noted that most precipitation events during this study were the result of isolated convective systems rather than associated with frontal activity. With the convective storms, a strong spatial gradient would not be expected in 20 -day averaged $\mathrm{Hg}$ concentrations measured at sites separated by relatively short distances $(<10 \mathrm{~km})$. However, spatial gradients may be seen in precipitation collected daily (individual events) at these sites, depending upon the source and transport of the feed air for each individual convective storm.

During this study, site-to-site differences in precipitation $\mathrm{Hg}$ concentrations were observed on several days. On 25 August air mass transport was from the east/southeast. Precipitation samples were collected at all four sites on this day, one of only two days during the entire study on which this occurred. Concentrations of $\mathrm{Hg}$ measured at the inland sites were all elevated when compared with site 1 located at the beach as seen in Figure 5. It is also clear from Figure 5 that a relationship existed between the measured concentrations of $\mathrm{Hg}, \mathrm{V}$, and $\mathrm{Ni}$ in the precipitation collected at sites 1,2 , and 4 (insufficient volume for ICP-MS analysis of the sample collected at site 3). Vanadium and nickel are both trace elements emitted during oil combustion (Gordon, 1988).

The levels of total $\mathrm{Hg}$ measured in event precipitation in this study were elevated 3 to 5 times over those made by the UMAQL in Vermont (Burke et al., 1995) or the Great Lakes Basin (Hoyer et al., 1995). However, it is difficult to make any definitive conclusions as to the source(s) responsible for the elevated levels of $\mathrm{Hg}$ in precipitation with the limited number of events collected during this study. 
TABLE I

Summary of $\mathrm{Hg}$ in Precipitation in $\mathrm{ng} / \mathrm{L}$ at Sites in Broward County, FL

\begin{tabular}{|lcccc|}
\hline & Site 1 & Site 4 & Site 2 & Site 3 \\
\hline Total Hg Mean & 35 & 57 & 40 & 46 \\
Std. Dev. & 16 & 15 & 19 & 28 \\
Range & $15-56$ & $43-81$ & $15-73$ & $14-130$ \\
N & 6 & 5 & 8 & 13 \\
& & & & \\
Reactive Hg Mean & 1.0 & 2.5 & 1.9 & 2.0 \\
Std. Dev. & 0.4 & 1.0 & 1.1 & 1.1 \\
Range & $0.5-1.4$ & $1.7-3.7$ & $0.8-3.3$ & $1.0-3.2$ \\
N & 4 & 4 & 5 & 4 \\
\hline
\end{tabular}

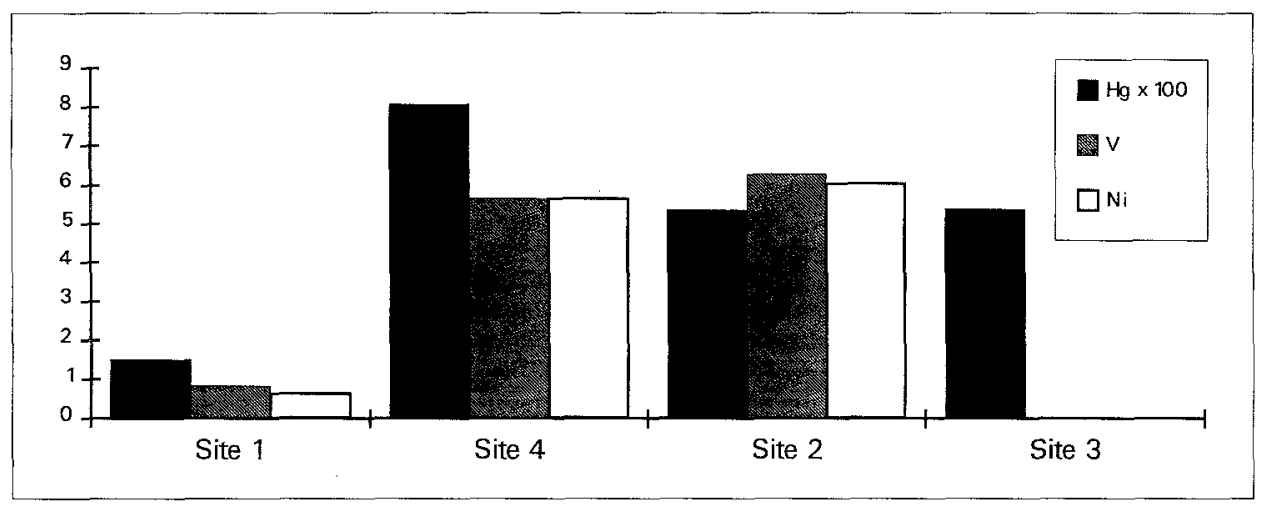

Fig. 5. Hg, V, and Ni in $\mu$ g/L Measured in Precipitation Collected in Broward County on 25 August, 1993

\section{Summary and Conclusions}

The data obtained from this pilot study indicate that levels of vapor and particle phase $\mathrm{Hg}$ measured at sites 2 (central) and 3 (house) were elevated above levels measured concurrently at site 1 (beach). One explanation for this is that a source, or sources, located near or between site 1 (beach) and site 2 (central) was impacting the portion of Broward County which lies west of site 2 . While the association of ambient $\mathrm{Hg}$ with $\mathrm{V}$ and $\mathrm{SO}_{2}$, combined with elevated $\mathrm{Hg}$ in precipitation being found with elevated $\mathrm{V}$ and $\mathrm{Ni}$ suggest an oil combustion source, the present study was not designed for source apportionment of the $\mathrm{Hg}$. Therefore, making any definitive conclusions as to the specific source(s) responsible for these elevated levels of $\mathrm{Hg}$ will require further meteorological analysis and a more complete characterization of the aerosol and precipitation composition.

Levels of total $\mathrm{Hg}$ in precipitation observed in daily event collections at several sites in Broward County during this study were significantly higher than those previously reported for more remote sites in southern Florida (Guentzel et al., 1994). The 
relatively large variation in $\mathrm{Hg}$ concentration measured simultaneously at multiple sites separated by relatively short distances $(<10 \mathrm{~km})$ suggests that more research is needed to adequately characterize atmospheric deposition to south Florida caused by sources in the two urbanized counties (Broward and Dade). The enhanced deposition in these areas may be quite important to the overall $\mathrm{Hg}$ loading to the sensitive ecosystems in south Florida due to the combination of the high amount of annual rainfall and high precipitation $\mathrm{Hg}$ concentrations.

Since wet deposition is the major removal process of atmospheric mercury, future studies in south Florida should include more comprehensive precipitation collection at a grid of sites in the two counties. Also, vapor and particulate measurements at selected sites would provide a better understanding of the processes leading to $\mathrm{Hg}$ in precipitation. In addition, a more detailed elemental analysis of both precipitation and particulate samples is needed to characterize the probable source(s) contributing to the increased deposition of mercury. The additional information obtained from the increased sampling and analysis would allow for a proper evaluation of the impact of local and regional source(s) to the $\mathrm{Hg}$ deposition to the region.

\section{Acknowledgments}

We would like to acknowledge the efforts of those involved in site preparation and sample collection, especially Ken Larson (BCDNRP) and Danny France (EPA Region IV). In addition, we thank Anne Rea, Janet Burke, and Marion Hoyer (UMAQL) for their contributions with sample analysis and data processing. Funding for this research was provided by the Florida Department of Environmental Protection.

\section{References}

Burke, J., Hoyer, M., Keeler, G., Scherbatskoy, T. (1995) this volume.

Dumarey R., Dams R. and Hoste J. (1985) Anal. Chem. 57:2638.

Dzubay, T.G., Stevens, R.K., Lewis, C.W., Hem, D.H., Courtney, W.J., Tesch, J.W., and Mason, M.A. (1982)

Environmental Science and Technology, 16:514.

Fitzgerald, W.F., and Gill, G.A. (1979) Anal. Chem., 51:1714.

Gordon, G.E. (1988) Environmental Science and Technology, 22:1132.

Guentzel, J.L. (1994) Presentation at "Conference on Mercury as a Global Pollutant" Whistler, British Colombia.

Hoyer, M. and Keeler, G. (1994) A Method for Automated Collection, Handling and Analysis of Mercury in Precipitation in a Multi-site Network, submitted to Environmental Science and Technology.

Hoyer, M., Burke, J., and Keeler, G. (1995) this volume.

Hand, J. and Friedemann, M. (1990) Mercury, Largemouth Bass, and Water Quality: A Preliminary Report. Florida Department of Environmental Regulation, Tallahassee, FL.

Keeler, G.J., Glinsorn, G., and Pirrone, N. (1995) this volume.

Keeler, G.J., Hoyer, M.E., Lamborg, C.H. (1994) In: Mercury as a Global Pollutant-Toward Integration and Synthesis. Watras, C.J., and Huckabee, J., Eds. In press.

Long, S.E. and Martin, T.D. (1992) In: Methods for the Determination of Metals in Environmental Samples. Environmental Monitoring Systems Laboratory, ORD-USEPA.

Lamborg, C.H., Hoyer, M.E., Keeler, G.J., Olmez, I., and Huang, X. (1994) In: Mercury as a Global PollutantToward Integration and Synthesis. Watras, C.J., and Huckabee, J., Eds. In press.

Roelke, M.E., Schultz, D.P., Facemire, C.F., Sundlof, S.F., and Royals, H.E. (1991) Mercury Contamination in Florida Panthers. Prepared by the Technical Subcommittee of the Florida Panther Interagency Committee.

Stevens, R.K., Drago, R.J., and Mamane, Y. (1993) Atmospheric Environment, 27B:231. 